Anna Claudine F. Lahoz, MD

Precious Eunice R. Grullo, MD, MPH

Ryner Jose C. Carrillo, MD, MSc ${ }^{1,2}$

'Department of Otorhinolaryngology

Philippine General Hospital

University of the Philippines Manila

2Department of Anatomy

College of Medicine

University of the Philippines Manila
Correspondence: Dr. Ryner Jose C. Carrillo

Department of Otorhinolaryngology

Philippine General Hospital

University of the Philippines Manila

Taft Avenue, Ermita, Manila 1000

Philippines

Phone: (632) 85548400 local 2152

Email Address: rynercarrillo@gmail.com

The authors declare that this represents original material, that the manuscript has been read and approved by all the authors, that the requirements for authorship have been met by each author, and that each author believes that the manuscript represents honest work.

Disclosures: The authors signed disclosures that there are no financial or other (including personal) relationships, intellectual passion, political or religious beliefs, and institutional affiliations that might lead to a conflict of interest. Reprints will not be available from the author.

Presented at the 2nd Congress of the Asia-Pacific Society of Thyroid Surgery. November 1-3, 2017 in Okinawa, Japan.

\section{Thyroglossal Duct Carcinoma with Concurrent Papillary Thyroid Carcinoma: A Case Report}

\begin{abstract}
Objective: To report a case of thyroglossal duct carcinoma with concurrent papillary thyroid carcinoma
\end{abstract}

Methods:

Design: Case Report

Setting: Tertiary National University Hospital

Patient: One

Results: A 46-year-old woman was diagnosed with thyroglossal duct carcinoma after undergoing a Sistrunk procedure. Due to presence of thyroid nodules, the patient underwent second stage thyroidectomy with central neck dissection which revealed papillary thyroid carcinoma.

Conclusion: Thyroglossal duct carcinomas are rare entities and there is no current consensus regarding their management. Difficulties arise in the diagnosis of these tumors as they present similarly to benign thyroglossal duct cysts. Most cases are diagnosed postoperatively. Proper preoperative assessment including head and neck examination, biopsy, and radiologic imaging is necessary to recognize patients who could benefit from more aggressive management.

\section{Keywords: thyroglossal carcinoma; thyroglossal duct cyst; papillary thyroid carcinoma}

Thyroglossal duct cysts are the most common developmental anomalies of the thyroid gland. They stem from the persistence of the tract of the migrating thyroid gland as it descends from its origin in the foramen cecum to its adult position inferior to the cricoid cartilage.' The thyroglossal duct cyst may contain remnants of thyroid tissue from which thyroid malignancies may arise. Thyroglossal duct carcinomas are rare malignancies accounting for $1 \%$ of all cases of thyroglossal duct tumors and may occur concurrently with thyroid malignancies. ${ }^{2}$ We present a case of papillary thyroid carcinoma in a thyroglossal duct cyst with a concurrent thyroid papillary carcinoma. 


\section{CASE REPORTS}

\section{CASE REPORT}

A 46-year-old woman presented with a three-year history of slowly growing anterior neck mass with no associated hypothyroid or hyperthyroid symptoms. There was no family history of carcinoma and the patient had no exposure to radiation. On physical examination, there was a $7 \times 6 \times 5.9 \mathrm{~cm}$ firm anterior neck mass located in the midline which moved with tongue protrusion. (Figure 1)

A neck ultrasonogram revealed a cystic mass in the anterior neck consistent with a thyroglossal duct cyst and normal thyroid glands. Fine needle aspiration biopsy revealed benign cyst contents and the patient underwent a Sistrunk procedure. Intraoperatively, there was note of a $6 \mathrm{x}$ $5 \times 4 \mathrm{~cm}$ cyst with solid areas adherent to the strap muscles (Figure 2) and an enlarged pre-laryngeal node. (Figure 3) Final histopathology results revealed classical variant papillary thyroid carcinoma, $4.2 \mathrm{~cm}$ in greatest tumor dimension, with extension to adjacent soft tissues. The enlarged pre-laryngeal node was positive for tumor.

On repeat neck ultrasonography done after the Sistrunk procedure, two cystic nodules were noted in the right thyroid lobe. The patient underwent a second stage total thyroidectomy with central neck dissection. Intraoperatively, the right thyroid lobe measured $4 \times 3 \times 2$ $\mathrm{cm}$ with multiple nodules palpable in the lobe. The left thyroid lobe measured $4 \times 2 \times 1 \mathrm{~cm}$ with no masses noted within the lobe. (Figure 4) There were no visible or palpable enlarged central lymph nodes.

Final histopathologic examination of the thyroidectomy specimen revealed multifocal classical variant papillary carcinoma of the right thyroid lobe and multinodular colloid goiter of the left thyroid lobe and isthmus. Level 6 lymph nodes were negative for tumor. The patient was scheduled to undergo radioactive iodine therapy but was lost to follow up.

\section{DISCUSSION}

The thyroid gland initially arises as a mass from a depression at the foramen cecum during the $5^{\text {th }}$ week of development. The thyroid gland migrates inferiorly and reaches its final adult position at the level below the cricoid cartilage during the $7^{\text {th }}$ week of development. ${ }^{1}$

The most common developmental anomalies of the thyroid gland are thyroglossal duct cysts which occur in $7 \%$ of the adult population. A thyroglossal duct cyst may develop if the tract of the descending thyroid fails to degenerate. The cyst may contain remnants of thyroid tissue from which malignancies may arise. ${ }^{3}$

Thyroglossal duct carcinomas are rare entities with an incidence of $<1 \%$ of all cases of thyroglossal duct cyst. ${ }^{2}$ Concurrent thyroglossal duct carcinomas and thyroid carcinomas have been reported to occur at a rate between $0-25 \% .{ }^{4}$ However, the true incidence is difficult to ascertain as not all patients undergo thyroidectomy. The most

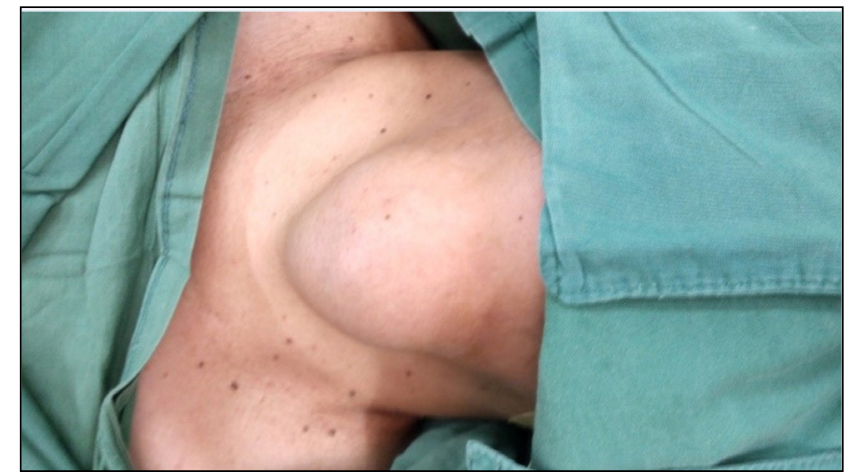

Figure 1. Preoperative picture of the patient showing a midline anterior neck mass

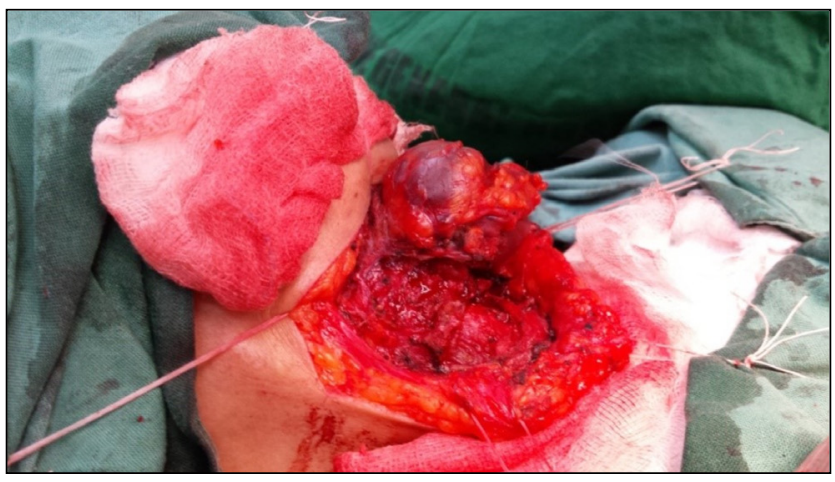

Figure 2. Thyroglossal duct cyst seen intraoperatively

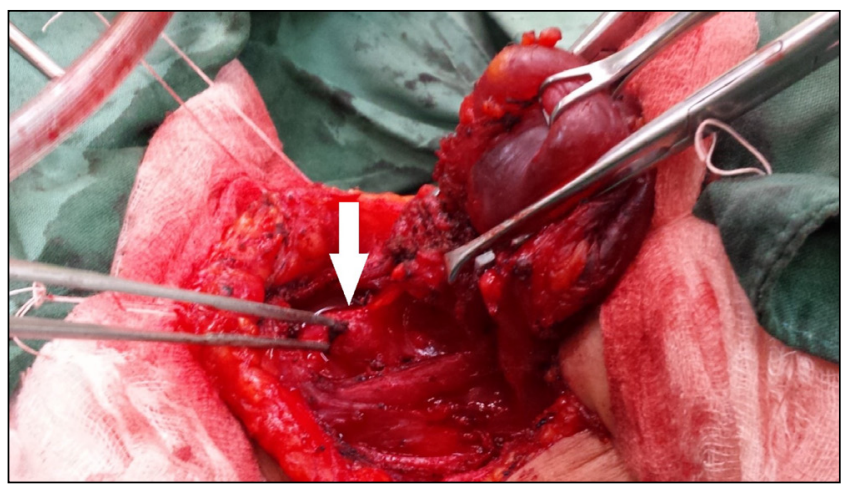

Figure 3. Arrow pointing to an enlarged pre-laryngeal node seen intraoperatively

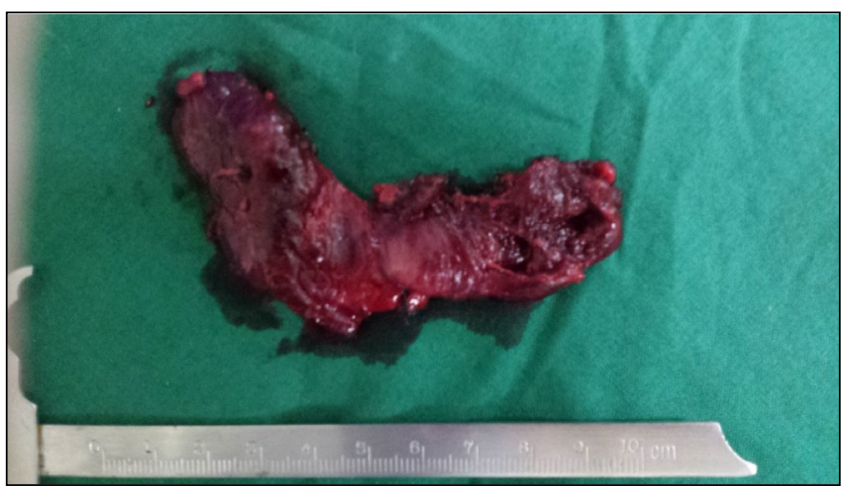

Figure 4. Resected thyroid gland 


\section{CASE REPORTS}

common histologic type of carcinoma found in thyroglossal duct cysts are papillary carcinomas but other types of carcinoma, such as mixed papillary-follicular, squamous cell, anaplastic, and Hurthle cell have been reported. ${ }^{5}$ There are no reported cases of medullary carcinomas found in thyroglossal duct cysts as medullary carcinomas arise from the parafollicular cells which have a different embryologic origin from the thyroid. ${ }^{6}$ This supports the theory that thyroglossal duct carcinomas arise de novo from the cyst itself. Two theories accounting for the origin of thyroglossal duct carcinomas are development of the carcinoma from thyroid tissue in the cyst and metastasis from a primary cancer in the thyroid gland?

Fine needle aspiration biopsy and neck ultrasound are standard diagnostic tests used for preoperative evaluation of midline neck masses. However, fine needle aspiration biopsy is often inaccurate when diagnosing thyroglossal duct carcinomas. ${ }^{8}$ Yang et al. reported a true positive rate of $53 \%$ and false negative rate of $47 \%$ for diagnosing thyroglossal duct carcinomas using fine needle aspiration biopsy. Ultrasound guided aspiration biopsy can improve accuracy of results. ${ }^{9}$ On ultrasonography, presence of a central solid component, calcifications, irregular borders, and thickened cyst walls are suggestive for carcinoma. However, they may be indistinguishable from benign TGDCs. ${ }^{5}$ Thyroglossal duct carcinomas are usually diagnosed postoperatively upon histopathologic examination of the operative specimen.

Frozen section examination of the specimen should be considered when malignancy is a consideration. Danilovic et al. recommended use of frozen section to diagnose papillary carcinoma due to poor sensitivity of FNAB. In their study, frozen section correctly diagnosed all cases of thyroglossal duct carcinomas based on suspicious findings on ultrasound. ${ }^{10}$

There is no current standard for treatment of thyroglossal duct carcinomas. Sistrunk procedure is usually done for thyroglossal duct carcinomas with some studies supporting its use as sufficient for treatment. The cure rate for papillary thyroglossal duct carcinomas has been reported at $95 \%$ when treated with Sistrunk procedure alone. Addition of total thyroidectomy with lymph node dissection increases the cure rate to $100 \% .{ }^{11}$ Some studies suggest performing a total thyroidectomy owing to the incidence of concurrent thyroid carcinoma with thyroglossal duct carcinomas. ${ }^{12}$ This highlights the importance of adequate preoperative evaluation for the patients. Radioactive iodine therapy has also been advised for patients with thyroglossal duct carcinomas however there is still no consensus for its use. ${ }^{13}$

Recent studies have proposed a risk stratification system to screen for high risk patients. More aggressive treatment is recommended if the patient has any of the following features: (1) age greater than 45 years,
(2) history of radiation exposure, (3) thyroid mass seen on imaging studies, (4) cervical lymphadenopathies evident clinically or on imaging studies, (5) tumor size greater than $1.5 \mathrm{~cm}$ in diameter, and (6) cyst wall invasion and positive margins on histopathologic examination. ${ }^{5}$

In conclusion, thyroglossal duct carcinomas are rare entities and there is no current consensus regarding its management. Difficulties arise in the diagnosis of these tumors as they present similarly to benign thyroglossal duct cysts. Most cases are diagnosed postoperatively. Proper preoperative assessment including proper head and neck examination, biopsy, and radiologic imaging is necessary to recognize patients who could benefit from more aggressive management.

\section{REFERENCES}

1. Chen EY, Sie KCY. Developmental anatomy. In: Flint PW, Haughey BH, Lund V, Niparko JK Robbins KT, Thomas JR, Lesperance MM (editors). Cummings Otolaryngology Sixth Edition Philadelphia, PA: Elsevier Saunders; 2015. p.2821-2830.

2. Patel SG, Escrig M, Shaha AR, Singh B, Shah JP. Management of a well-differentiated thyroid carcinoma presenting within a thyroglossal duct cyst. J Surg Oncol. 2002 Mar;79(3):134-9; discussion 140-1. DOI: 10.1002/jso.10059; PMID: 11870661

3. Nugent A, El-Deiry M. Differential diagnosis of neck masses. In: Flint PW, Haughey BH, Lund V Niparko JK, Robbins KT, Thomas JR, Lesperance MM (editors). Cummings Otolaryngology Sixth Edition. Philadelphia, PA: Elsevier Saunders; 2015. p.2821-2830.

4. Tew S, Reeve TS, Poole AG, Delbridge L. Papillary thyroid carcinoma arising in thyroglossal duct cysts: incidence and management. Aust NZ J Surg. 1995 Oct; 65(10):717-8. DOI: 10.1111/j.1445 2197. 1995 tb00543 x. PMID: 7487710.

5. Kermani W, Belcadhi M, Abdelkefi M, Bouzouita K. Papillary carcinoma arising in a thyroglossa duct cyst: case report and discussion of management modalities. Eur Arch Otorhinolaryngol. 2008 Feb; 265(2): 233-6. DOI: 10.1007/s00405-007-0405-y; PMID: 17668227.

6. Kandogan T, Erkan N, Vardar E. Papillary carcinoma arising in a thyroglossal duct cyst with associated microcarcinoma of the thyroid and without cervical lymph node metastasis: a case report. J Med Case Rep. 2008 Feb 8; 2:42. DOI: 10.1186/1752-1947-2-42; PMID: 18257934 PMCID: PMC2262906.

7. Rossi ED, Martini M, Straccia P, Cocomazzi A, Pennacchia I, Revelli L, et al. Thyroglossal duct cyst cancer most likely arises from a thyroid gland remnant. Virchows Arch. 2014 Jul; 465(1): 67-72 DOI: 10.1007/s00428-014-1583-9; PMID: 24777145.

8. Aculate NR, Jones HB, Bansal A, Ho MW. Papillary carcinoma within a thyroglossal duct cyst: significance of a central solid component on ultrasound imaging. Br J Oral Maxillofac Surg. 2014 Mar; 52(3): 277-8. DOI: 10.1016/j.bjoms.2013.10.003; PMID: 24210780.

9. Yang YJ, Haghir S, Wanamaker JR, Powers CN. Diagnosis of papillary carcinoma in a thyroglossal duct cyst by fine needle aspiration biopsy. Arch Pathol Lab Med. 2000 Jan; 124(1): 139-142. DOI 10.1043/0003-9985(2000)124<0139:DOPCIA>2.0.CO;2; PMID: 10629147.

10. Danilovic DL, Marui S, Lima EU, Luiz AV, Brescia MD, Moyses RA, et al. Papillary carcinoma in thyroglossal duct cyst: role of fine needle aspiration and frozen section biopsy to guide surgical approach. Endocrine 2014 May; 46 (1):160-3. DOI: 10.1007/s12020-014-0173-6; PMID: 24493029

11. Choi YM, Kim TY, Song DE, Hong SJ, Jang EK, Jeon MJ, et al. Papillary thyroid carcinoma arising from a thyroglossal duct cyst: a single institution experience. Endocrine J. 2013; 60 (5):665-670. DOI: 10.1507/endocri.ej12-0366; PMID: 23318645.

12. Gebbia V, Di Gregorio C, Attard M. Thyroglossal duct cyst carcinoma with concurrent thyroid carcinoma: a case report. J Med Case Reports. 2008 Apr 29; 2:132. DOI: 10.1186/1752-1947-2 132. PMID: 18445281 PMCID: PMC2387158.

13. Sobri FB, Ramli M, Sari UN, Umar M, MudrickDK. Papillary Carcinoma Occurence in a Thyroglossal Duct Cyst with Synchronous Papillary Thyroid Carcinoma without Cervical Lymph Node Metastasis: Two-Cases Report. Case Rep Surg. 2015; 2015:872054. DOI: 10.1155/2015/872054 PMID: 25785223 PMCID: PMC4345054. 